\title{
Isolated Limb Perfusion and External Beam Radiotherapy for Soft Tissue Sarcomas of the Extremity: Long-Term Effects on Normal Tissue According to the LENT-SOMA Scoring System
}

\author{
Miriam L. Hoven-Gondrie, MD, ${ }^{1}$ Katja M. J. Thijssens, MD, PhD, ${ }^{1}$ \\ Jan H. B. Geertzen, MD, PhD, ${ }^{2}$ Elisabeth Pras, MD, PhD, ${ }^{3}$ Robert J. van Ginkel, MD, PhD, ${ }^{1}$ \\ and Harald J. Hoekstra, MD, $\mathrm{PhD}^{1}$
}

\footnotetext{
${ }^{1}$ Department of Surgical Oncology, University Medical Center Groningen, University of Groningen, P.O. Box 30.001, Groningen 9700 RB, The Netherlands

${ }^{2}$ Department of Rehabilitation, University Medical Center Groningen, University of Groningen, P.O. Box 30.001, Groningen 9700 RB, The Netherlands

${ }^{3}$ Department of Radiotherapy, University Medical Center Groningen, University of Groningen, P.O. Box 30.001, Groningen 9700 RB, The Netherlands
}

\begin{abstract}
Background: With the combined treatment procedure of isolated limb perfusion (ILP), delayed surgical resection and external beam radiotherapy (EBRT) for locally advanced soft tissue sarcomas (STS) of the extremities, limb salvage rates of more than $80 \%$ can be achieved. However, long-term damage to the healthy surrounding tissue cannot be prevented. We studied the late effects on the normal tissue using the LENT-SOMA scoring system.

Patients and Methods: A total of 32 patients - median age 47 (range 14-71) years - were treated for a locally advanced STS with ILP, surgical resection and often adjuvant 60-70 Gy EBRT. After a median follow-up of 88 (range 17-159) months, the patients were scored, using the LENT-SOMA scales, for the following late tissue damage: muscle/soft tissue, peripheral nerves, skin/subcutaneous tissue and vessels.

Results: According to the individual SOM parameters of the LENT-SOMA scales, 20 patients $(63 \%)$ scored grade- 3 toxicity on one or more separate items, reflecting severe symptoms with a negative impact on daily activities. Of these patients, $3(9 \%)$ even scored grade-4 toxicity on some of the parameters, denoting irreversible functional damage necessitating major therapeutic intervention.

Conclusions: In evaluating long-term morbidity after a combined treatment procedure for STS of the extremity, using modified LENT-SOMA scores, two-thirds of patients were found to have experienced serious late toxic effects.

Key Words: Sarcoma-Perfusion-Radiation-LENT-SOMA—Complications.
\end{abstract}

In the 1960s and 1970s, the effectiveness of (neo)adjuvant isolated limb perfusion (ILP) with various cytostatics was explored in the limb salvage

Published online March 11, 2008.

Address correspondence and reprint requests to: Harald $\mathbf{J}$. Hoekstra, MD, PhD; E-mail: h.j.hoekstra@chir.umcg.nl

Published by Springer Science+Business Media, LLC ๑ 2008 The Author(s) treatment of extremity sarcomas. ${ }^{1}$ The practice of performing extremity perfusions for sarcomas ended after Rosenberg showed the effectiveness of adjuvant radiation treatment in limb salvage. Amputations or exarticulations of the affected limb did not result in higher survival rates., ${ }^{2,3}$

There was a renewed interest in neoadjuvant ILP in the early 1990s, when Lejeune and co-workers added 
tumor necrosis factor alpha $(\mathrm{TNF} \alpha)$ to Melphalan in the ILP treatment of locally advanced extremity melanomas and sarcomas. This resulted in high local response rates and high limb salvage rates with an acceptable local and systemic toxicity. ${ }^{4,5}$

Currently, an established limb salvage strategy for primarily irresectable soft tissue sarcomas (STSs) of the limbs consists of induction treatment with hyperthermic ILP with TNF $\alpha$ and Melphalan, followed by delayed surgical resection and, in case of marginal or non-radical resection, adjuvant external beam radiotherapy (EBRT). With this combined treatment modality, short-term limb salvage rates of more than $80 \%$ are achieved, with long-term rates of $60 \%{ }^{5,6}$ However, as the number of long-term cancer survivors increases, late complications of therapy will become an increasingly important concern. ${ }^{7}$ Long-term damage to the healthy surrounding tissue cannot be prevented. Toxic effects of pre- or postoperative EBRT and intra-arterial chemotherapy have been extensively described in previous literature and include edema, fibrosis, neuropathy, limited mobility, impaired wound healing and, less commonly, pain, bone fractures and second tumors. ${ }^{3,8-11}$ Moreover, during ILP, normal tissue in the limb - skin, subcutaneous tissue, muscle, nerves, blood vessels, bone and cartilage - is exposed to the same concentrations of cytostatic agents active against the tumor, causing regional toxic effects, which lead to comparable late complications. ${ }^{12}$ Recently, we described the late vascular complications that occur after the TNF ILP treatment procedure. ${ }^{13}$ Functional morbidity and symptoms such as edema and pain can also be extremely invalidating, sometimes necessitating aggressive treatment. To evaluate all toxic long-term effects, we used the uniform, generally accepted toxicity scoring system "LENT-SOMA". This system not only allows late damage to be classified in different gradations, but also allows data acquisition using three different methods: (1) subjective, the injury is recorded as perceived by the patient; (2) objective, morbidity is assessed during a clinical examination; and (3) management, indicates the active steps made to ameliorate the symptoms. ${ }^{14}$ In order to provide an overview of all late toxic effects on the limb treated with ILP, delayed surgical resection and adjuvant high-dose EBRT, a retrospective study was conducted to evaluate long-term morbidity using the LENT-SOMA scoring system.

\section{PATIENTS AND METHODS}

Between 1991 and 2003, 73 patients with locally advanced STSs underwent 77 perfusions with a combination of TNF $\alpha$ and Melphalan, with $(n=19)$ or without $(n=58)$ interferon-gamma (IFN $\gamma)$, at the Division of Surgical Oncology of the University Medical Center Groningen (UMCG). The perfusion technique has been previously described extensively. ${ }^{15,16}$ Currently, 39 patients are still alive and in follow-up. There were 7 patients who were unable to participate because of severe or advanced (co-)morbidity $(n=2)$ or non-medical reasons $(n=5)$. Consequently, 32 patients, 14 males (44\%) and 18 females $(56 \%)$, median age 47 (range 14-71) years, could be evaluated (response rate $82 \%$ ). Of all the 32 patients, 5 had STSs of the upper extremity (16\%), treated with an axillary perfusion. In the remaining 27 , they were located in the lower limb $(84 \%)$ and were treated with iliacal $(n=13,41 \%)$, femoral $(n=5,16 \%)$ or popliteal $(n=9,28 \%)$ perfusion. There were 27 primary $(84 \%)$ and 5 recurrent (16\%) STSs.

After a median post-perfusion duration of 8 (range 6-12) weeks, all patients underwent a delayed local resection of the tumor remnant. Of the patients, 25 had clear microscopic surgical margins (R0 resection, $78 \%$ ) and 7 had histologically positive microscopic margins (R1 resection, 22\%). No patient had macroscopic residual disease. A total of 24 patients $(75 \%)$ with marginal $(\leq 1 \mathrm{~cm}, n=17)$ or microscopically positive resection $(n=7)$ margins received adjuvant high dose (60-70 Gy) postoperative EBRT in 25 fractions of $2 \mathrm{~Gy}$, followed by a boost of 10-20 Gy. One patient with a recurrent STS received EBRT at the time of treatment of the primary tumor, but not after ILP and resection of the recurrence. Adjuvant systemic chemotherapy was given to 7 patients: 2 due to the definite histopathological classification of the tumor (one embryonal rhabdomyosarcoma and one extraosseal osteosarcoma); 3 as part of an EORTC trial (EORTC 62931); ${ }^{17}$ and 2 in a palliative setting because of distant metastasis.

All patients received a tailored post-surgical rehabilitation program, during and after the radiation treatment, until a final result was achieved. All patients were treated after informed consent was obtained according to institutional guidelines. A total of 12 different histological types of STS were distinguished. The pathological grade and stage of the tumor were scored according to the criteria of Coindre et al. and the American Joint Committee on Cancer (AJCC), respectively. ${ }^{18,19}$ Patient and tumor characteristics are summarized in Table 1.

Local status of the treated limb was first globally assessed using a checklist including the following items: lymphedema, color, stiffness, hypesthesia, 
TABLE 1. Characteristics of patients. PNET primitive neuroectodermal tumor, PUS pleiomorphic undifferentiated sarcoma, MPNST malignant peripheral nerve sheath tumor, FU follow-up in months, na not available

\begin{tabular}{|c|c|c|c|c|c|c|c|c|c|}
\hline Age (years) & Sex & & Histology & Grade & AJCC stage & Level & EBRT & Amputation & $\mathrm{FU}$ \\
\hline 18 & Female & Primary & Embryonal rhabdomyosarcoma & 3 & 3 & Iliacal & No & No & 159 \\
\hline 44 & Female & Recurrent & Myxoid liposarcoma & 1 & 1 & Iliacal & Yes & No & 152 \\
\hline 43 & Male & Primary & Synovial sarcoma & 3 & 3 & Iliacal & Yes & No & 151 \\
\hline 18 & Male & Primary & Myxoid chondrosarcoma & 2 & 3 & Popliteal & Yes & Yes & 149 \\
\hline 48 & Female & Primary & Well-differentiated liposarcoma & 1 & 1 & Iliacal & Yes & No & 143 \\
\hline 56 & Female & Primary & PNET & 3 & 3 & Iliacal & Yes & Yes & 137 \\
\hline 50 & Female & Recurrent & PUS & 3 & 3 & Popliteal & No & No & 135 \\
\hline 44 & Male & Primary & Myxoid liposarcoma & 1 & 1 & Iliacal & Yes & No & 131 \\
\hline 24 & Male & Recurrent & Synovial sarcoma & 2 & 3 & Popliteal & Yes & No & 129 \\
\hline 37 & Female & Primary & MPNST & 2 & 3 & Axillary & Yes & No & 121 \\
\hline 48 & Male & Primary & Myxoid liposarcoma & 2 & 3 & Iliacal & Yes & No & 111 \\
\hline 63 & Female & Recurrent & PUS & 2 & 3 & Popliteal & No & Yes & 107 \\
\hline 37 & Male & Primary & Myxoid liposarcoma & 1 & 1 & Iliacal & Yes & No & 105 \\
\hline 58 & Male & Primary & PUS & 2 & 3 & Iliacal & Yes & No & 98 \\
\hline 71 & Female & Primary & Leiomyosarcoma & 1 & 1 & Femoral & No & No & 94 \\
\hline 56 & Female & Primary & PUS & 3 & 3 & Popliteal & Yes & No & 61 \\
\hline 63 & Male & Primary & Myxoid chondrosarcoma & na & 3 & Femoral & Yes & No & 50 \\
\hline 37 & Female & Primary & Leiomyosarcoma & 1 & 1 & Femoral & Yes & No & 36 \\
\hline 28 & Male & Primary & Synovial sarcoma & 2 & 3 & Femoral & Yes & No & 36 \\
\hline 57 & Female & Primary & PUS & 3 & 3 & Femoral & Yes & No & 35 \\
\hline 42 & Female & Primary & Synovial sarcoma & 2 & 3 & Iliacal & Yes & Yes & 32 \\
\hline 47 & Female & Primary & PUS & 3 & 3 & Axillary & Yes & No & 30 \\
\hline 58 & Female & Primary & PUS & 3 & 3 & Popliteal & Yes & No & 26 \\
\hline 27 & Male & Primary & Epithelioid sarcoma & 3 & 4 & Axillary & Yes & No & 26 \\
\hline 71 & Male & Recurrent & Myxoid fibrosarcoma & 1 & 1 & Axillary & No & No & 24 \\
\hline 56 & Female & Primary & PUS & 3 & 3 & Axillary & No & No & 22 \\
\hline 14 & Male & Primary & PUS & 3 & 3 & Popliteal & Yes & No & 20 \\
\hline 65 & Female & Primary & Synovial sarcoma & 2 & 3 & Popliteal & No & Yes & 18 \\
\hline 63 & Male & Primary & Synovial sarcoma & 3 & 3 & Iliacal & Yes & No & 17 \\
\hline 71 & Male & Primary & Rhabdomyosarcoma & 3 & 3 & Iliacal & Yes & No & 17 \\
\hline
\end{tabular}

paresthesia, muscle atrophy, pain, scar status, function and use of aids.

Late effects on surrounding tissue were graded according to the subjective, objective and management portions of the LENT-SOMA scales, as proposed by the EORTC and RTOG Late Effects Working Group in 1995. ${ }^{14,20,21}$ Four LENT-SOMA scales were used: muscle/soft tissue, peripheral nerves, skin/subcutaneous tissue and vessels. ${ }^{22}$ Not all patients could be scored on all four items, since in 5 patients $(16 \%)$ the affected limb was amputated.

\section{RESULTS}

After a median follow-up of 88 (range 17-159) months, 14 patients $(44 \%)$ mentioned one or more locoregional complaints in the treated leg, mainly consisting of pain, spasm and limitation of mobility. Scoring the local status using a checklist, deviating symptoms and signs were documented and are summarized in Table 2 . Only 15 patients $(47 \%)$ did not use any aids; the remaining $17(53 \%)$ needed elastic compression stockings, braces, prostheses or crutches.
TABLE 2. Local status in 32 patients: deviating symptoms and signs

\begin{tabular}{lrr}
\hline \multicolumn{1}{c}{ Symptom } & No. & $\%$ \\
\hline Lymphedema & 14 & 44 \\
Discoloration & 18 & 56 \\
Stiffness & 16 & 50 \\
Atrophy & 27 & 84 \\
Pain & 5 & 16 \\
Hypesthesia & 17 & 53 \\
Paresthesia & 13 & 41 \\
Function & & \\
$\quad$ - Limited & 18 & 56 \\
- Severely limited & 4 & 13 \\
\hline
\end{tabular}

\section{LENT-SOMA Scales}

Results of scoring late tissue effects according to the LENT-SOMA scoring system are listed below and illustrated in Table 3. Grade 1 represents the most minor symptoms, which do not require treatment. Grade 2 represents moderate symptoms, requiring only conservative treatment. Grade 3 represents severe symptoms, which have a significant negative impact on daily activities and require more aggressive treatment. Grade 4 represents irreversible 
TABLE 3. Modified LENT-SOMA scores

\begin{tabular}{|c|c|c|c|c|c|c|c|c|c|c|}
\hline & \multicolumn{10}{|c|}{ Maximum grade of toxicity } \\
\hline & \multicolumn{2}{|c|}{0} & \multicolumn{2}{|c|}{1} & \multicolumn{2}{|c|}{2} & \multicolumn{2}{|c|}{3} & \multicolumn{2}{|c|}{4} \\
\hline \multicolumn{11}{|c|}{ Muscle/ soft tissue $(n=31)$} \\
\hline Subjective & 6 & $19 \%$ & 9 & $29 \%$ & 2 & $6 \%$ & 14 & $45 \%$ & 0 & $0 \%$ \\
\hline Objective & 0 & $0 \%$ & 0 & $0 \%$ & 15 & $48 \%$ & 16 & $52 \%$ & 0 & $0 \%$ \\
\hline Management & 20 & $65 \%$ & 1 & $3 \%$ & 9 & $29 \%$ & 1 & $3 \%$ & 0 & $0 \%$ \\
\hline \multicolumn{11}{|c|}{ Peripheral nerves $(n=30)$} \\
\hline Subjective & 6 & $20 \%$ & 3 & $10 \%$ & 9 & $30 \%$ & 12 & $40 \%$ & 0 & $0 \%$ \\
\hline Objective $^{a}$ & 6 & $21 \%$ & 12 & $43 \%$ & 7 & $25 \%$ & 3 & $11 \%$ & 0 & $0 \%$ \\
\hline Management & 23 & $77 \%$ & 1 & $3 \%$ & 4 & $13 \%$ & 2 & $7 \%$ & 0 & $0 \%$ \\
\hline \multicolumn{11}{|c|}{ Skin/subcutaneous tissue $(n=27)$} \\
\hline Subjective & 8 & $30 \%$ & 15 & $56 \%$ & 2 & $7 \%$ & 2 & $7 \%$ & 0 & $0 \%$ \\
\hline Objective & 1 & $4 \%$ & 6 & $22 \%$ & 15 & $56 \%$ & 5 & $19 \%$ & 0 & $0 \%$ \\
\hline Management & 23 & $85 \%$ & 0 & $0 \%$ & 0 & $0 \%$ & 2 & $7 \%$ & 2 & $7 \%$ \\
\hline \multicolumn{11}{|l|}{ Vessels $(n=25)$} \\
\hline Subjective & 16 & $64 \%$ & 4 & $16 \%$ & 4 & $16 \%$ & 1 & $4 \%$ & 0 & $0 \%$ \\
\hline Objective & 13 & $52 \%$ & 8 & $32 \%$ & 2 & $8 \%$ & 1 & $4 \%$ & 1 & $4 \%$ \\
\hline Management & 18 & $72 \%$ & 4 & $16 \%$ & 0 & $0 \%$ & 1 & $4 \%$ & 2 & $8 \%$ \\
\hline
\end{tabular}

TABLE 4. LENT-SOMA scores for muscle/soft tissue $(n=31)$

\begin{tabular}{|c|c|c|c|c|c|c|c|c|c|c|c|c|}
\hline & \multicolumn{12}{|c|}{ Grade of toxicity } \\
\hline & \multicolumn{2}{|c|}{0} & \multicolumn{2}{|c|}{1} & \multicolumn{2}{|c|}{2} & \multicolumn{2}{|c|}{3} & \multicolumn{2}{|c|}{4} & \multicolumn{2}{|c|}{ NA } \\
\hline \multicolumn{13}{|l|}{ Subjective } \\
\hline - Pain & 20 & $65 \%$ & 7 & $23 \%$ & 2 & $6 \%$ & 2 & $6 \%$ & 0 & $0 \%$ & 0 & $0 \%$ \\
\hline - Function & 6 & $19 \%$ & 9 & $29 \%$ & 2 & $6 \%$ & 14 & $45 \%$ & 0 & $0 \%$ & 0 & $0 \%$ \\
\hline \multicolumn{13}{|l|}{ Objective } \\
\hline - Edema & 14 & $45 \%$ & 10 & $32 \%$ & 4 & $13 \%$ & 2 & $6 \%$ & 0 & $0 \%$ & 1 & $3 \%$ \\
\hline - Mobility and extremity function & 6 & $19 \%$ & 9 & $29 \%$ & 11 & $35 \%$ & 5 & $16 \%$ & 0 & $0 \%$ & 0 & $0 \%$ \\
\hline - Fibrosis & 1 & $3 \%$ & 3 & $10 \%$ & 15 & $48 \%$ & 10 & $32 \%$ & 0 & $0 \%$ & 0 & $0 \%$ \\
\hline - Atrophy & 0 & $0 \%$ & 3 & $10 \%$ & 16 & $52 \%$ & 10 & $32 \%$ & 0 & $0 \%$ & 2 & $6 \%$ \\
\hline - Contraction & 18 & $58 \%$ & 0 & $0 \%$ & 12 & $39 \%$ & 0 & $0 \%$ & 0 & $0 \%$ & 1 & $3 \%$ \\
\hline \multicolumn{13}{|l|}{ Management } \\
\hline - Pain & 25 & $81 \%$ & 3 & $10 \%$ & 3 & $10 \%$ & 0 & $0 \%$ & 0 & $0 \%$ & 0 & $0 \%$ \\
\hline - Edema & 24 & $77 \%$ & 0 & $0 \%$ & 5 & $16 \%$ & 1 & $3 \%$ & 0 & $0 \%$ & 1 & $3 \%$ \\
\hline - Mobility and extremity function & 27 & $87 \%$ & 1 & $3 \%$ & 2 & $6 \%$ & 1 & $3 \%$ & 0 & $0 \%$ & 0 & $0 \%$ \\
\hline - Fibrosis & 29 & $94 \%$ & 1 & $3 \%$ & 0 & $0 \%$ & 0 & $0 \%$ & 0 & $0 \%$ & 1 & $3 \%$ \\
\hline - Atrophy & 29 & $94 \%$ & 0 & $0 \%$ & 1 & $3 \%$ & 0 & $0 \%$ & 0 & $0 \%$ & 1 & $3 \%$ \\
\hline
\end{tabular}

functional damage, necessitating major therapeutic intervention. SOMA stands for: S, subjective complaints; $\mathrm{O}$, objective symptoms; and $\mathrm{M}$, management and therapy.

\section{Muscle/Soft Tissue}

Of the patients, 6 experienced no subjective toxic effects $(19 \%), 9$ scored maximum grade $1(29 \%), 2$ scored grade $2(6 \%)$ and 14 had a maximum of grade- 3 toxicity $(45 \%)$. When scored objectively, a maximum of grade- 2 toxicity was found in 15 patients $(48 \%)$ and grade 3 in 16 patients $(52 \%)$. No patient had only minor or no symptoms. No treatment was required in 20 patients $(65 \%), 1$ patient $(3 \%)$ scored grade 1 (occasional physiotherapy), 9 scored grade $2(29 \%)$ and $1(3 \%)$ needed continued medical intervention (grade 3) for edema and extremity malfunction. A detailed overview of all items is provided in Table 4.

\section{Peripheral Nerves}

No subjective toxic effects were observed in 6 patients $(20 \%), 3$ scored maximum grade- 1 toxicity $(10 \%), 9$ scored grade $2(30 \%)$ and 12 grade- 3 toxicity $(40 \%)$. When scored objectively, 6 patients experienced no toxicity ( $21 \%$ ), and 12 scored grade- 1 $(43 \%), 7$ grade- $2(25 \%)$ and 3 grade-3 $(11 \%)$ toxic effects. Of the patients, 23 did not require any treatment $(77 \%), 1(3 \%)$ scored grade-1 (occasional nonnarcotic), 4 (13\%) grade-2 (regular non- narcotic) and $2(7 \%)$ grade- 3 (physical or medical intervention because of severe motor dysfunction) toxicity. A detailed overview is provided in Table 5. 
TABLE 5. LENT-SOMA scores for peripheral nerves $(n=30)$

\begin{tabular}{|c|c|c|c|c|c|c|c|c|c|c|c|c|}
\hline & \multicolumn{12}{|c|}{ Grade of toxicity } \\
\hline & \multicolumn{2}{|c|}{0} & \multicolumn{2}{|c|}{1} & \multicolumn{2}{|c|}{2} & \multicolumn{2}{|c|}{3} & \multicolumn{2}{|c|}{4} & \multicolumn{2}{|c|}{ NA } \\
\hline \multicolumn{13}{|l|}{ Subjective } \\
\hline - Pain & 20 & $67 \%$ & 7 & $23 \%$ & 1 & $3 \%$ & 2 & $7 \%$ & 0 & $0 \%$ & 0 & $0 \%$ \\
\hline - Strength & 7 & $23 \%$ & 1 & $3 \%$ & 12 & $40 \%$ & 8 & $27 \%$ & 0 & $0 \%$ & 2 & $7 \%$ \\
\hline - Sensory & 10 & $33 \%$ & 11 & $37 \%$ & 2 & $7 \%$ & 6 & $20 \%$ & 0 & $0 \%$ & 1 & $3 \%$ \\
\hline - Motor paresis & 14 & $47 \%$ & 8 & $27 \%$ & 5 & $17 \%$ & 2 & $7 \%$ & 0 & $0 \%$ & 1 & $3 \%$ \\
\hline \multicolumn{13}{|l|}{ Objective } \\
\hline - Motor dysfunction & 7 & $23 \%$ & 11 & $37 \%$ & 7 & $23 \%$ & 2 & $7 \%$ & 1 & $3 \%$ & 2 & $7 \%$ \\
\hline - Sensory dysfunction & 12 & $40 \%$ & 12 & $40 \%$ & 3 & $10 \%$ & 1 & $3 \%$ & 0 & $0 \%$ & 2 & $7 \%$ \\
\hline - Reflex & 17 & $57 \%$ & 7 & $23 \%$ & 3 & $10 \%$ & 0 & $0 \%$ & 0 & $0 \%$ & 3 & $10 \%$ \\
\hline \multicolumn{13}{|l|}{ Management } \\
\hline - Pain & 22 & $73 \%$ & 3 & $10 \%$ & 4 & $13 \%$ & 0 & $0 \%$ & 0 & $0 \%$ & 1 & $3 \%$ \\
\hline - Motor dysfunction & 25 & $83 \%$ & 0 & $0 \%$ & 0 & $0 \%$ & 2 & $7 \%$ & 0 & $0 \%$ & 3 & $10 \%$ \\
\hline - Sensory dysfunction & 27 & $90 \%$ & 0 & $0 \%$ & 0 & $0 \%$ & 0 & $0 \%$ & 0 & $0 \%$ & 3 & $10 \%$ \\
\hline - Sensory & 27 & $90 \%$ & 0 & $0 \%$ & 0 & $0 \%$ & 0 & $0 \%$ & 0 & $0 \%$ & 3 & $10 \%$ \\
\hline
\end{tabular}

TABLE 6. LENT-SOMA scores for skin/subcutaneous tissue $(n=27)$

\begin{tabular}{|c|c|c|c|c|c|c|c|c|c|c|c|c|}
\hline & \multicolumn{12}{|c|}{ Grade of toxicity } \\
\hline & \multicolumn{2}{|c|}{0} & \multicolumn{2}{|r|}{1} & \multicolumn{2}{|c|}{2} & \multicolumn{2}{|r|}{3} & \multicolumn{2}{|c|}{4} & \multicolumn{2}{|c|}{ NA } \\
\hline \multicolumn{13}{|l|}{ Subjective } \\
\hline - Scaliness/ roughness & 9 & $33 \%$ & 16 & $59 \%$ & 0 & $0 \%$ & 2 & $7 \%$ & 0 & $0 \%$ & 0 & $0 \%$ \\
\hline - Sensation & 20 & $74 \%$ & 5 & $19 \%$ & 2 & $7 \%$ & 0 & $0 \%$ & 0 & $0 \%$ & 0 & $0 \%$ \\
\hline \multicolumn{13}{|l|}{ Objective } \\
\hline - Edema & 11 & $41 \%$ & 8 & $30 \%$ & 5 & $19 \%$ & 2 & $7 \%$ & 0 & $0 \%$ & 1 & $4 \%$ \\
\hline - Alopecia (scalp) & 9 & $33 \%$ & 13 & $48 \%$ & 3 & $11 \%$ & 1 & $4 \%$ & 0 & $0 \%$ & 1 & $4 \%$ \\
\hline - Pigmentation change & 6 & $22 \%$ & 8 & $30 \%$ & 11 & $41 \%$ & 1 & $4 \%$ & 0 & $0 \%$ & 1 & $4 \%$ \\
\hline - Ulcer/necrosis & 25 & $93 \%$ & 1 & $4 \%$ & 1 & $4 \%$ & 0 & $0 \%$ & 0 & $0 \%$ & 0 & $0 \%$ \\
\hline - Teleangiectasia & 16 & $59 \%$ & 7 & $26 \%$ & 3 & $11 \%$ & 0 & $0 \%$ & 0 & $0 \%$ & 1 & $4 \%$ \\
\hline - Fibrosis/scar & 2 & $7 \%$ & 19 & $70 \%$ & 6 & $22 \%$ & 0 & $0 \%$ & 0 & $0 \%$ & 0 & $0 \%$ \\
\hline - Atrophy/ contraction & 2 & $7 \%$ & 15 & $56 \%$ & 6 & $22 \%$ & 2 & $7 \%$ & 0 & $0 \%$ & 2 & $7 \%$ \\
\hline \multicolumn{13}{|l|}{ Management } \\
\hline - Dryness & 23 & $85 \%$ & 1 & $4 \%$ & 1 & $4 \%$ & 1 & $4 \%$ & 0 & $0 \%$ & 1 & $4 \%$ \\
\hline - Sensation & 26 & $96 \%$ & 0 & $0 \%$ & 0 & $0 \%$ & 0 & $0 \%$ & 0 & $0 \%$ & 1 & $4 \%$ \\
\hline - Ulcer & 26 & $96 \%$ & 0 & $0 \%$ & 0 & $0 \%$ & 0 & $0 \%$ & 1 & $4 \%$ & 0 & $0 \%$ \\
\hline - Edema & 25 & $93 \%$ & 0 & $0 \%$ & 0 & $0 \%$ & 2 & $7 \%$ & 0 & $0 \%$ & 0 & $0 \%$ \\
\hline - Fibrosis/scar & 26 & $96 \%$ & 0 & $0 \%$ & 0 & $0 \%$ & 0 & $0 \%$ & 1 & $4 \%$ & 0 & $0 \%$ \\
\hline
\end{tabular}

\section{Skin/Subcutaneous Tissue}

No subjective symptoms were observed in 8 patients (30\%), 15 scored maximum grade- 1 toxicity $(56 \%), 2$ grade $2(7 \%)$ and $2(7 \%)$ grade 3 (scaliness/roughness requiring constant attention). Only 1 patient experienced no objective toxicity ( $4 \%$ ), while 6 scored grade 1 $(22 \%), 15$ grade $2(56 \%)$ and 5 grade $3(19 \%)$. No treatment was required in 23 patients $(85 \%)$, but 2 $(7 \%)$ required medical intervention because of edema and dryness (grade-3 toxicity) and 2 (7\%) scored grade-4 toxicity - surgical intervention due to massive fibrosis and a persistent ulcer requiring surgical therapy. A detailed overview is provided in Table 6.

\section{Vessels}

No subjective symptoms were observed in 16 patients (64\%), while 4 scored maximum grade-1 (16\%),
4 grade-2 (16\%) and 1 grade-3 (4\%) toxicity: clinical symptoms of ischemia at rest. Objective symptoms were absent in 13 patients $(52 \%)$, but 8 patients scored grade- 1 toxicity (32\%), 2 scored grade $2(8 \%), 1$ grade 3 (intense ischemia) (4\%) and 1 grade 4 (necrosis) $(4 \%)$. No form of management was needed in 18 patients $(72 \%)$. However, 4 patients scored grade 1 $(16 \%), 1(4 \%)$ grade 3 (conservative surgery because of arterial disease) and $2(8 \%)$ required amputation (grade-4 toxicity) because of critical leg ischemia. A detailed overview is provided in Table 7.

Overall, outcomes from the Subjective and Objective symptoms are different from those of the Management part of the LENT-SOMA scales. According to the subjective and objective parts of the scale, two-thirds of patients had serious late toxic side effects concerning any of the surrounding normal tissue. A grade-3 
TABLE 7. LENT-SOMA scores for vessels $(n=25)$

\begin{tabular}{|c|c|c|c|c|c|c|c|c|c|c|c|c|}
\hline & \multicolumn{12}{|c|}{ Grade of toxicity } \\
\hline & \multicolumn{2}{|c|}{0} & \multicolumn{2}{|c|}{1} & \multicolumn{2}{|c|}{2} & \multicolumn{2}{|c|}{3} & \multicolumn{2}{|c|}{4} & \multicolumn{2}{|c|}{ NA } \\
\hline \multicolumn{13}{|l|}{ Subjective } \\
\hline - Ärterial & 20 & $80 \%$ & 1 & $4 \%$ & 3 & $12 \%$ & 1 & $4 \%$ & 0 & $0 \%$ & 0 & $0 \%$ \\
\hline - Venous & 20 & $80 \%$ & 4 & $16 \%$ & 1 & $4 \%$ & 0 & $0 \%$ & 0 & $0 \%$ & 0 & $0 \%$ \\
\hline \multicolumn{13}{|l|}{ Objective } \\
\hline - Arterial & 22 & $88 \%$ & 0 & $0 \%$ & 1 & $4 \%$ & 1 & $4 \%$ & 1 & $4 \%$ & 0 & $0 \%$ \\
\hline - Venous & 16 & $64 \%$ & 8 & $32 \%$ & 1 & $4 \%$ & 0 & $0 \%$ & 0 & $0 \%$ & 0 & $0 \%$ \\
\hline \multicolumn{13}{|l|}{ Management } \\
\hline - Arterial & 22 & $88 \%$ & 0 & $0 \%$ & 0 & $0 \%$ & 1 & $4 \%$ & 2 & $8 \%$ & 0 & $0 \%$ \\
\hline - Venous & 21 & $84 \%$ & 4 & $16 \%$ & 0 & $0 \%$ & 0 & $0 \%$ & 0 & $0 \%$ & 0 & $0 \%$ \\
\hline
\end{tabular}

toxicity was scored by 17 patients $(53 \%)$ on one or more items of the subjective parts of the four used scales. They experienced their long-term morbidity as severe and with a negative impact on daily activities. Grade- 3 or -4 toxicity was scored by 18 patients $(56 \%)$ on the objective parts of the scoring scales, showing severe or irreversible damage during a clinical examination. However, according to the management parts, 16 patients $(50 \%)$ scored no toxicity (grade 0 ) on all management items of the four used LENT-SOMA scales and did not require any treatment. Moreover, 9 patients $(28 \%)$ scored a maximum grade- 1 or -2 toxicity and only needed conservative treatment. In less than a quarter of patients $(n=7,22 \%)$, aggressive treatment, e.g., continuous medical intervention or surgery, was necessary due to long-term effects of the combined treatment procedure.

\section{DISCUSSION}

The limb-sparing treatment strategy of ILP using TNF and Melphalan - with or without adjuvant EBRT - is increasingly being pursued for locally advanced STS of the extremities after the publication of the results of a European multi-center trial performed in the 1990s. Using this combined treatment modality, excellent short-term limb salvage rates of more than $80 \%$ and long-term rates of $60 \%$ can be achieved with no negative impact on survival. ${ }^{5,6}$ While, at first, selected groups of patients were often excluded from undergoing this procedure, limb preservation has now become a major challenge for all patients with a locally advanced STS.

It seems to be a safe and highly effective procedure in elderly patients, for whom every attempt to avoid an amputation that may end their independence must be considered..$^{23}$ It can also be used in a palliative setting for patients who present with distant metastasis at the time of diagnosis, as better local control improves the quality of life. ${ }^{24}$ In patients with multifocal primary or multiple recurrent extremity sarcomas, ILP also provides excellent local control and limb salvage rates of more than $80 \%$ are achieved. ${ }^{25}$

However, acute toxicity and long-term morbidity due to the combined treatment procedure of ILP, surgical resection and EBRT cannot be prevented. In ILP, normal tissue in the limb is exposed to the same concentrations of cytostatic agents as the tumor. The effects of the perfusate on normal tissue vary widely among individuals and long-term morbidity also varies widely in severity.

As far as we know, this is the first study to assess late functional morbidity with the LENT-SOMA scales in patients treated for STS with ILP, surgical resection and EBRT.

\section{Neurotoxicity}

Neuropathy is particularly important and is mainly seen after the use of specific cytostatic perfusion agents, such as cisplatin, carboplatin and doxorubicin. $^{26-28}$ Furthermore, nerve damage can be caused by initial tumor swelling or pressure from the tight tourniquet. ${ }^{29,30}$ A prophylactic fasciotomy can prevent the occurrence of a persistent neurotoxicity with motor-sensory neuropathy and is routinely performed in our series. ${ }^{31}$ Radiotherapy also plays an important role, especially when patients have received a boost. ${ }^{32}$ All our patients received a boost of 10- 20 Gy EBRT. Despite the fact that neurotoxicity was subjectively found to be severe in $40 \%$ of patients, only in $11 \%$ could it be objectified, and in only $7 \%$ was physical or medical intervention needed. None of the patients had paralysis or complete anesthesia or needed surgical intervention.

\section{Functional Morbidity}

Functional outcome after limb-sparing treatment with ILP has been analyzed previously, but mostly in 
melanoma patients and not using a uniform scoring system. Other studies show limitations in ankle joint mobility in $25-40 \%$ of patients, compared with no significant objective limitations in previous investigations in our study population. ${ }^{12,33}$ The routinely performed fasciotomy, combined with an intensive physiotherapy program, might explain these better outcomes because the regional toxic effects of ILP are hereby reduced. ${ }^{34}$ In this study, we found muscle atrophy in almost all patients (96\%), which may be due to an extensive surgical resection having been performed after ILP for deep-seated STSs, in contrast to the mostly superficial resection in melanoma patients. Only 4 patients (13\%) still needed medical intervention: occasional or regular physiotherapy. However, 14 patients $(44 \%)$ found that their limb function interfered with daily activities. In only 6 patients (19\%) could no functional impairment be objectified.

\section{Scoring Systems}

Most previous studies evaluating functional outcome after treatment for STS included no ILP, but consisted of wide local excision with or without postoperative EBRT and/or adjuvant chemotherapy. Gerrand et al. found a significant decrease in functional scores when the revised Musculoskeletal Tumor Society Rating Scale (MSTS) and Toronto Extremity Salvage Score (TESS) were used after treatment of deep-seated tumors ${ }^{35}$. In two studies, the LENTSOMA scales were used to assess functional morbidity after wide local excision and EBRT sometimes combined with chemotherapy for STS. The LENTSOMA scales were found to be time-consuming, but reliable for a detailed description of late toxicity. ${ }^{32,36}$

To evaluate the long-term morbidity in our study, we used this generally accepted LENT-SOMA scoring system. According to Denekamp et al., no overall LENT score is calculated but all criteria are separately described in order to prevent the high scores being filtered out, thus giving a falsely optimistic picture. ${ }^{37}$ Although primarily developed to analyze late radiation effects, it can also be used to score the toxicity of chemotherapy. ${ }^{21}$ In this study, 25 of the 32 patients analyzed $(78 \%)$ received EBRT. The 3 patients who scored grade- 4 toxicity on one or more items all received EBRT. Overall, there was no patient who did not experience any late toxic effect.

\section{Quality of Life}

All functional complaints can have a substantial negative impact on daily functioning, which brings into question whether expectations of the time-consuming technically demanding limb-sparing treatment are upheld. Previous studies showed no improved quality of life with limb-sparing surgery compared with that after amputation. ${ }^{38,39}$ The long rehabilitation period is a disadvantage of a limbsparing treatment strategy, but the impact of a prosthesis should not be underestimated. Thijssens et al. recently showed a worse physical functioning and more role limitations in amputated patients in this study population. Attention to collaborative decision making and communication with the patient seem very important. ${ }^{40}$

\section{Future Perspectives}

Every effort should be made to prevent long-term morbidity in the future. As long-term morbidity seems to be correlated to acute regional toxic reactions, these acute reactions should be reduced as far as possible. ${ }^{30}$ Improved perfusion technique and enhanced technical insights have led to the following suggestions: reduce the doses of TNF $\alpha$, decrease systemic leakage, reduce maximum temperatures and strictly regulate perfusion pressures. ${ }^{15,30,41}$ To prevent the significant toxicity related to muscle and nerve damage, a prophylactic fasciotomy should be performed in all cases and the isolating tourniquet should not be applied too tightly. ${ }^{30,31}$ Furthermore, all patients should receive an individualized rehabilitation program to achieve an optimum functional situation.

Finally, a lot of long-term morbidity after EBRT is subscribed to the occurrence of radiation-induced fibrosis, which was thought to be irreversible. ${ }^{7}$ Thanks to the pioneering work of Delanian et al., there is growing knowledge that radiation-induced fibrosis is at least partially reversible by administering drugs with antioxidant and anti-fibrotic properties, such as pentoxifylline and vitamin E. Large randomized trials are, however, needed to confirm these findings. ${ }^{32}$

In conclusion, the Subjective, Objective, and Management parts of the LENT-SOMA scoring system confirm late toxic effects on surrounding normal tissue in all patients treated with a combined treatment modality for locally advanced STS of the extremity. Two-thirds of the patients have severe Subjective or Objective damage, but half of all patients do not require any Management for their symptoms. To prevent long-term morbidity in the future, efforts should be made to reduce acute toxic reactions after ILP, and a fasciotomy and a customized rehabilitation program are recommended. Furthermore, anti-fibrotic therapies might be considered. 


\section{OPEN ACCESS}

This article is distributed under the terms of the Creative Commons Attribution Noncommercial License which permits any noncommercial use, distribution, and reproduction in any medium, provided the original author(s) and source are credited.

\section{REFERENCES}

1. Hoekstra HJ, Schraffordt Koops H, Molenaar WM, et al. Results of isolated regional perfusion in the treatment of malignant soft tissue tumours of the extremities. Cancer 1987; 60:1703-7.

2. Rosenberg SA, Tepper J, Glatstein E, et al. The treatment of soft-tissue sarcomas of the extremities: prospective randomized evaluations of (1) limb sparing surgery plus radiation therapy compared with amputation and (2) the role of adjuvant chemotherapy. Ann Surg 1982; 196:305-15.

3. Yang JC, Chang AE, Baker AR, et al. Randomized prospective study of the benefit of adjuvant radiation therapy in the treatment of soft tissue sarcomas of the extremity. J Clin Oncol 1998; 16:197-203.

4. Lejeune FJ, Pujol N, Liénard D, et al. Limb salvage by neoadjuvant isolated perfusion with TNF $\alpha$ and melphalan for nonresectable soft tissue sarcoma of the extremities. Eur J Surg Oncol 2000; 26:669-78.

5. Eggermont AM, Schraffordt Koops H, Lienard D, et al. Isolated limb perfusion with high-dose tumor necrosis factoralpha in combination with interferon-gamma and melphalan for nonresectable extremity soft tissue sarcomas: a multicenter trial. J Clin Oncol 1996; 14:2653-65.

6. Van Ginkel RJ, Thijssens KJM, Pras E, et al. Isolated limb perfusion with TNF and Melphalan for locally advanced soft tissue sarcoma: three time periods at risk for amputation. Ann Surg Oncol 2007; 14:1499-506.

7. Anscher MS. The irreversibility of radiation-induced fibrosis: Fact or folklore? J Clin Oncol 2005; 23:8551-2.

8. Thijssens KJM, van Ginkel RJ, Pras E, et al. Isolated limb perfusion with tumor necrosis factor $\alpha$ and Melphalan for locally advanced soft tissue sarcoma: the value of adjuvant radiotherapy. Ann Surg Oncol 2006; 13:1-7.

9. Davis AM, Turcotte R, Bell R, et al. Preoperative versus postoperative radiotherapy in soft-tissue sarcoma of the limbs: a randomised trial. Lancet 2002; 359:2235-41.

10. Nijhuis PH, Pras E, Sleijfer DT, et al. Long-term results of preoperative intra-arterial doxorubicin combined with neoadjuvant radiotherapy, followed by extensive surgical resection for locally advanced soft tissue sarcomas of the extremities. Radiother Oncol 1999; 51:15-9.

11. Singer S, Demetri GD, Baldini EH, et al. Management of softtissue sarcomas: an overview and update. Lancet Oncol 2000 $1: 75-85$.

12. Vrouenraets BC, in't Veld GJ, Nieweg OE, et al. Long-term functional morbidity after mild hyperthermic isolated limb perfusion with melphalan. Eur J Surg Oncol 1999; 25:503-8.

13. Hoven-Gondrie ML, Thijssens KMJ, et al. Long-term locoregional vascular morbidity after isolated limb perfusion and external beam radiotherapy for soft tissue sarcoma of the extremity. Ann Surg Oncol 2007; 14:2105-12.

14. Pavy JJ, Denekamp J, Letschert J, et al. Late effects toxicity scoring: The SOMA scale. Int J Radiat Oncol Biol Phys 1995; 31:1043-7.

15. Van Ginkel RJ, Limburg PC, Piers DA, et al. Value of continuous leakage monitoring with radioactive Iodine-131labeled human serum albumin during hyperthermic isolated limb perfusion with tumor necrosis factor- $\alpha$ and Melphalan. Ann Surg Oncol 2002; 9:355-63.

16. Olieman AFT, Pras E, van Ginkel RJ, et al. Feasibility and efficacy of external beam radiotherapy after hyperthermic isolated limb perfusion with TNF $\alpha$ and Melphalan for limbsaving treatment in locally advanced extremity soft-tissue sarcoma. Int J Radiat Oncol Biol Phys 1998; 40:807-14.

17. Woll PJ, van Glabbeke M, Hohenberger P, et al. Adjuvant chemotherapy (CT) with doxorubicin and ifosfamide in resected soft tissue sarcoma (STS): interim analysis of a randomised phase III trial. Proceed ASCO 2007.

18. Coindre JM, Trojani M, Contesso G, et al. Reproducibility of a histopathologic grading system for adult soft tissue sarcoma. Cancer 1986; 58:306-309.

19. AJCC Cancer Staging Manual. Springer Verlag, New York, 2002.

20. Mornex F, Pavy JJ, Denekamp J, et al. Scoring system of late effects of radiations on normal tissues: the SOMA-LENT scale. Cancer Radiother 1997; 1:622-68.

21. Rubin P, Constine LS, Fajardo LF, et al. RTOG Late effects working group. Overview. Late effects of normal tissue (LENT) scoring system. Int J Radiat Oncol Biol Phys 1995; 31:1041-2.

22. LENT SOMA scales for all anatomic sites. Int $J$ Radiat Oncol Biol Phys 1995;31:1049-91.

23. Van Etten B, van Geel AN, de Wilt JHW, et al. Fifty tumor necrosis factor-based isolated limb perfusions for limb salvage in patients older than 75 years with limb-threatening soft tissue sarcomas and other extremity tumors. Ann Surg Oncol 2003; $10: 32-7$.

24. Olieman AFT, van Ginkel RJ, Molenaar WM, et al. Hyperthermic isolated limb perfusion with tumour necrosis factor $\alpha$ and melphalan as palliative limb-saving treatment in patients with locally advanced soft-tissue sarcomas of the extremities with regional or distant metastases. Is it worthwhile? Arch Orthop Trauma Surg 1998; 118:70-4.

25. Grunhagen DJ, Brunstein F, Graveland WJ, et al. Isolated limb perfusion with tumor necrosis factor and melphalan prevents amputation in patients with multiple sarcomas in arm or leg. Ann Surg Oncol 2005; 12:473-9.

26. Hoekstra HJ, Schraffordt Koops H, de Vries LG, et al. Toxicity of hyperthermic isolated limb perfusion with cisplatin for recurrent melanoma of the lower extremity after previous perfusion treatment. Cancer 1993; 72:1224-9.

27. Daryanani D, de Vries EGE, Guchelaar HJ, et al. Hyperthermic isolated regional perfusion of the limb with carboplatin. Eur J Surg Oncol 2000; 26:792-7.

28. Di Fillipo F, Garinei R, Anza M, et al. Doxorubicin in isolation limb perfusion in the treatment of advanced limb soft tissue sarcoma. $J$ Exp Clin Cancer Res 2003; 22(4 Suppl):81-7.

29. Noorda EM, Vrouenraets BC, Nieweg OE, et al. Isolated limb perfusion with tumor necrosis factor- $\alpha$ and Melphalan for patients with unresectable soft tissue sarcoma of the extremities. Cancer 2003; 98:1483-90.

30. Vrouenraets BC, Klaase JM, Kroon BB, et al. Long-term morbidity after regional isolated perfusion with melphalan for melanoma of the limbs. The influence of acute regional toxic reactions. Arch Surg 1995; 130:43-7.

31. Schraffordt Koops H. Prevention of neural and muscular lesions during hyperthermic regional perfusion. Surg Gynecol Obstet 1972; 135:401-3.

32. Milbeo Y, Kantor G, Laharie H, et al. Adjuvant radiation therapy for soft tissue sarcoma of the extremities: analysis of local control according to volume and dose. Cancer Radiother 2005; 9:293-303.

33. van Geel AN, van Wijk J, Wieberdink J. Functional morbidity after regional isolated perfusion of the limb for melanoma. Cancer 1989; 63:1092-6.

34. Olieman AFT, Schraffordt Koops H, Geertzen JHB, et al. Functional morbidity of hyperthermic isolated regional perfusion of the extremities. Ann Surg Oncol 1994; 1:382-388. 
35. Gerrand CH, Wunder JS, Kandel RA, et al. The influence of anatomic location on functional outcome in lower-extremity soft-tissue sarcoma. Ann Surg Oncol 2004; 11:476-82.

36. Tawfiq N, Lagarde P, Stöckle E, et al. Conservative treatment of soft tissue sarcomas of the extremities. Functional evaluation with LENT-SOMA scales and the Enneking score. Cancer Radiother 2000; 4:421-7.

37. Denekamp J, Bartelink H, Rubin P. Correction for the use of the SOMA LENT tables. Int J Radiat Oncol Biol Phys 1996; $35: 417$.

38. Sugarbaker PH, Barofsky I, Rosenberg SA, et al. Quality of life assessment of patients in extremity sarcoma clinical trials. Surgery 1982; 91:17-23.
39. Zahlten-Hinguranage A, Bernd L, Ewerbeck V, et al. Equal quality of life after limb-sparing or ablative surgery for lower extremity sarcomas. Br J Cancer 2004; 91:1012-4.

40. Thijssens KM, Hoekstra- Weebers JE, van Ginkel RJ, et al. Quality of life after hyperthermic isolated limb perfusion for locally advanced extremity soft tissue sarcoma. Ann Surg Oncol 2006; 13:864-71.

41. Fontijne WP, Mook PH, Koops HS, et al. Improved tissue perfusion during pressure regulated hyperthermic regional isolated perfusion. A clinical study. Cancer 1985; 55:1455-61.

42. Delanian S, Lefaix JL. Current management for late normal tissue injury: radiation-induced fibrosis and necrosis. Semin Radiat Oncol 2007; 17:99-107. 